\title{
Dengue and Dengue Hemorrhagic Fever
}

\author{
Maysaa Abdallah Saeed ${ }^{1}$, Tarek Hamed Attia ${ }^{2}$ \\ ${ }^{I}$ Tropical Medicine Department, Faculty of Medicine, Zagazig University, Egypt \\ ${ }^{2}$ Pediatric Department, Faculty of Medicine, Zagazig University, Egypt
}

\section{Corresponding Author Maysaa Abdallah Saeed}

E mail:

dr.maysaaabdallah@w indowslive.com

Key words: flaviviruses, dengue virus, hemorrhagic fever
Dengue is endemic in at least 100 countries in Asia, the Pacific, the Americas, Africa, and the Caribbean. The World Health Organization (WHO) estimates that 50 to 100 million infections occur yearly, including 500,000 dengue hemorrhagic fever (DHF) cases and 22,000 deaths, mostly among children. Both epidemic and endemic transmission of dengue viruses are maintained through a human-mosquito-human cycle involving mosquitoes of the genus Aedes (Stegomyia). Typical clinical manifestations of dengue range from self-limited dengue fever (DF) to dengue hemorrhagic fever with shock

\section{HISTORY}

Because of dengue fever nonspecific clinical features, the interpretation of historical records for evidence of past epidemic is open to speculation. However, Benjamin Rush's description of a 1780 Philadelphia epidemic was the earliest description in English of so called break-bone fever. Subsequently, sporadic outbreaks were reported throughout the tropics and subtropics [1].

In 1903 Mosquito borne transmission of dengue virus infection by $A$. aegypti was demonstrated and its viral etiology in 1906. Sabin demonstrated the failure of two viral strains to cross protect humans, while isolating the virus in 1944, thus establishing the existence of dengue virus serotypes. Hammons characterized two more serotypes in 1956. After World War II, the start of a pandemic with transmission of multiple viral serotypes began in Southeast Asia, leading to outbreaks of dengue hemorrhagic fever [1]. syndrome. Most dengue virus infections in adults are symptomatic. In contrast, most infections among children under age 15 years are asymptomatic or minimally symptomatic. Classic dengue fever is an acute febrile illness accompanied by malaise, headache, retro orbital pain, and marked muscle and joint pains, which evoked the term "break-bone fever". DHF is the most serious manifestation of dengue virus infection and can be associated with circulatory failure and shock. Plasma leakage is the most specific and life-threatening feature of DHF.

\section{EPIDEMIOLOGY}

Dengue is endemic in at least 100 countries in Asia, the Pacific, the Americas, Africa, and the Caribbean. The World Health Organization (WHO) estimates that 50 to 100 million infections occur yearly, including 500,000 DHF cases and 22,000 deaths, mostly among children [2].

Dengue viruses are members of the family Flaviviridae, genus Flavivirus $[\mathbf{3 , 4}]$. They are small, enveloped viruses containing a singlestrand RNA genome of positive polarity [3]. A.aegypti breed in or close to houses, laying eggs in both man-made and natural water containers. The typical flight distance is relatively short [5]. A. aegypti are day time feeders that prefer to bite humans and are frequently unnoticed. For this reason, family members who are at home during the daytime, typically women and young children, are at particularly high risk for infection [6]. 


\section{TRANSMISSION CYCLE}

Both epidemic and endemic transmission of dengue viruses are maintained through a humanmosquito-human cycle involving mosquitoes of the genus Aedes (Stegomyia) [7].Susceptible humans become infected after being bitten by an infected female Aedes mosquito. Viremia in humans begins toward the end of a four- to sixday incubation period and persists until fever abates, which is typically three to seven days [8,9]. An uninfected Aedes mosquito may acquire the virus after feeding during this viremic period. The mosquito has an incubation period of 8 to 12 days before it is capable of transmitting the virus to susceptible individuals. Once infected, mosquitoes carry the virus for their lifespan and remain infective for humans.

In rare cases dengue can be transmitted in organ transplants or blood transfusions from infected donors, and it can be transmitted by accidental needle stick [10]. Vertical transmission from an infected pregnant mother to her fetus has been reported [11]. But in the vast majority of infections, a mosquito bite is responsible.

\section{PATTERNS OF TRANSMISSION}

Dengue virus transmission follows two general (but not mutually exclusive) patterns

\section{Epidemic dengue}

Epidemic dengue transmission occurs when the introduction of dengue virus into a region is an isolated event involving a single virus strain.

\section{Hyper endemic dengue}

"Hyper endemic" transmission refers to the continuous circulation of multiple dengue virus serotypes in the same area.

\section{FACTORS INFLUENCING TRANSMISSION}

The worldwide incidence of dengue and DHF has been increasing in the past several decades, and the geographic distribution of these diseases has expanded.

The transmission cycle for dengue viruses is dependent upon the interaction between infective mosquitoes and susceptible humans and between susceptible mosquitoes and viremic humans.
Dengue virus transmission is enhanced by the following factors [7]:

1- Increased vector density: In many tropical countries, seasonal increases in rainfall contribute to an increased density of mosquitoes. In addition higher humidity lengthens mosquitos' lifespan [12].

2- Shorter mosquito incubation: The extrinsic incubation period is inversely associated with the ambient temperature. Warmer temperatures increase the length of time that a mosquito remains infective.

3- Increased movement of mosquito vectors and viruses: Air, land, and water transportation of mosquitoes or viremic humans facilitate the dissemination of dengue viruses.

4- Increased density of susceptible hosts: Crowded conditions probably increase the potential for virus transmission.

5- Increased duration and magnitude of viremia in humans.

\section{PATHOGENESIS}

After an infectious mosquito bite, the virus replicates in local lymph nodes and within 2 to 3 days disseminates via the blood to various tissues. Virus circulates in the blood typically for 5 days in infected monocytes/macrophages and to a lesser degree in $\mathrm{B}$ cells and $\mathrm{T}$ cells. It also replicates in skin, reactive spleen lymphoid cells, and macrophages $[\mathbf{1 3}, \mathbf{1 4}]$.

Malaise and flue like symptoms that characterize dengue probably reflect patients 'cytokine response; however myalgia, a cardinal features of the illness, may also indicate pathologic changes in the muscle, typified by a moderate perivascular mononuclear infiltrate with lipid accumulation [15]. Musculoskeletal pain(break-bone fever) conceivably could reflect viral infection of bone marrow elements, including mobile macrophages and dendritic cells (CD11blCD18 [MAC-11]positive) and relatively non motile adventitial reticular cells (nerve growth factor receptorpositive).Local suppression of erythrocytic, myelocytic, and thrombocytic poiesis within 4 to 5 days is reflected in peripheral cytopenias. Histopathological examination of skin from patient with rash discloses a minor degree of 
lymphocytic dermal vasculitis and, variably, viral antigen [13,9].

Neurologic complications have attributed chiefly to metabolic alterations and to focal and sometimes massive intracranial hemorrhages, but anecdotal cases and limited case series have indicated the possibility of viral CNS invasion and encephalitis [16,17].

Shock in dengue shock syndrome (DSS) occurs after the sudden extravasation of plasma into extravascular sites, including the pleural and abdominal cavities, usually with the defervescence of fever $[\mathbf{1 8 , 1 9 ]}$. The extensive increase in vascular permeability is associated with immune activation, as manifested by increased levels of plasmasoluble tumor necrosis factor receptor (sTNFR 175), IL-28, interferon, and local endothelial production of IL-28 RANTES with apoptotic endothelial cell death $[\mathbf{2 0 , 2 1 ]}$. In addition immune complex formation activates the complement system, with increase in C3a and C5a [22]. Levels of IL-6 and intercellular adhesion molecule-1 are depressed in parallel with hypoalbuminemia and the general loss of serum proteins. Reduced cardiac output may contribute further to shock [23].

The hemorrhagic diathesis is complex and not well understood, reflecting a combination of cytokine action and vascular injury, viral antibodies' binding to platelets or cross reacting with plasminogen and other clotting factors, reduced platelet function and survival, and a mild consumptive coagulopathy $[\mathbf{2 4 , 2 5 , 2 6 , 2 7 ]}$.

The increased frequency of DHF in secondary dengue virus infection has suggested a role for heterologous antibodies in enhancing viral uptake and replication in fc receptor- bearing cells (antibody mediated immune enhancement) $[\mathbf{2 8 , 2 9 ]}$. Simultaneously, levels of TNF-alpha, soluble CD8, and soluble IL-2 that are higher in patient with DHF than in those with dengue fever indicate an activation of cross reactive memory $\mathrm{CD} 4^{+}$and $\mathrm{CD}^{+} \mathrm{T}$ cells in response to a second infection [20].

\section{CLINICAL MANIFESTATIONS}

Typical clinical manifestations of dengue range from self-limited dengue fever (DF) to dengue hemorrhagic fever with shock syndrome [30]. With wider availability of laboratory testing, there are increasing reports of unusual clinical manifestations, as discussed below [31]. The risk of severe disease is much higher in repeated infection than primary infection [32].

\section{Asymptomatic infection}

Most dengue virus infections in adults are symptomatic [33]. In contrast, most infections among children under age 15 years are asymptomatic or minimally symptomatic. In one study of schoolchildren in rural Thailand, 53 percent of dengue virus infections were not associated with a recognized febrile illness despite intense active surveillance [11]. Dengue virus type 2 and 4 may be more likely to cause inapparent infection in flavivirus naïve person [34].

\section{Classic dengue fever}

Classic dengue fever is an acute febrile illness accompanied by malaise, headache, retro orbital pain, and marked muscle and joint pains, which evoked the term "break-bone fever" [35]. Symptoms typically develop between 4 and 7 days after the bite of an infected mosquito; the incubation period may range from 3 to 14 days. Dengue can essentially be excluded as the cause of symptoms in a traveler who develops illness more than 14 days after returning from a dengue-endemic country [36].

Fever typically lasts for five to seven days. Some patients have a biphasic ("saddleback") fever curve, with the second febrile phase lasting one to two days; this has been described in approximately 5 percent of patients $[37,38]$. The febrile period may also be followed by a period of marked fatigue that can last for days to weeks, especially in adults.

The frequency and severity of symptoms was influenced by the patient's age and sex and differed in patients with primary versus secondary dengue virus infection. All symptoms were less frequent in patients $\leq 19$ years of age. Joint pain, body aches, and rash were more common in females. Constitutional symptoms and gastrointestinal symptoms were more common in patients experiencing a second infection, whereas rash was more commonly noted during primary infection [39]. Disease severity may be increased among infants and elderly [40].

Vertical transmission of dengue virus to neonates whose mother has an onset of primary or second dengue fever zero to 8 days before delivery has resulted in acute neonatal dengue manifesting as fever, cyanosis, apnea, mottling, hepatomegaly and thrombocytopenia $[\mathbf{1 1}, \mathbf{4 1}]$. The outcome of infection acquired earlier in pregnancy has not been addressed satisfactorily. Previous reports have described spontaneous abortion, variety of 
birth defects and, in post epidemic investigation, an increase in neural tube defects [42].

\section{Hemorrhagic manifestations}

Hemorrhagic manifestations occur commonly in patients with DF and, in rare cases, can be life threatening. In a large study in Thailand, spontaneous bleeding occurred in 68 percent of children with DF [43]. The main bleeding sites were the skin (58 percent) and nose (19 percent); gastrointestinal bleeding was less common (4 percent). In another series of 18 adults who acquired DF during travel, hemorrhagic phenomena were noted in 22 percent; two patients had purpura and two had melena [37].

\section{Other symptoms}

Acute dengue virus infection often presents without the full picture of classical DF, especially in children. Gastrointestinal or respiratory tract symptoms may dominate the clinical picture in some patients [39]. Hepatitis frequently complicate dengue fever [44]. Neurologic symptoms have been reported sporadically and attributed to hemorrhage and cerebral edema in addition to the possibility of primary dengue encephalitis $[16,17,45,46]$. Myositis with rhabdomyolysis has also been reported [1].

\section{Physical examination}

Physical examination in patients with DF is generally nonspecific. Conjunctival injection, pharyngeal erythema, lymphadenopathy, and hepatomegaly are observed in 20 to 50 percent of patients [47]. The rash is typically macular or maculopapular and may be associated with pruritus.

\section{Laboratory findings}

Laboratory findings typical of DF include the following: Leukopenia is common in both adults and children with DF and is a useful diagnostic feature $[\mathbf{4 7 , 4 8 , 4 9 ]}$. Thrombocytopenia is noted in most patients with DF [50]. In several studies, platelet counts $<100,000$ cells $/ \mathrm{mm}^{3}$ were observed in 16 to 55 percent of patients. Serum aspartate transaminase (AST) levels are frequently elevated in both adults and children with DF; the elevations are usually modest ( 2 to 5 times the upper limit of normal values), but marked elevations (5 to 15 times the upper limit of normal) are occasionally noted $[\mathbf{4 7 , 4 8}]$.

\section{Dengue hemorrhagic fever}

Dengue hemorrhagic fever (DHF) is the most serious manifestation of dengue virus infection and can be associated with circulatory failure and shock. The four cardinal features of DHF, as defined by the World Health Organization (WHO), include [31,32,51]: 1-Increased vascular permeability (plasma leakage syndrome) that lead to hemo concentration (20 percent or greater rise in hematocrit above baseline value), pleural effusion, or ascites, 2-Marked thrombocytopenia $\left(100,000\right.$ cells $/ \mathrm{mm}^{3}$ or lower), 3-Fever lasting two to seven days, 4-A hemorrhagic tendency (as demonstrated by a positive tourniquet test) or spontaneous bleeding.

The term dengue shock syndrome (DSS) is used when shock is present along with these four criteria. The period of maximum risk for shock is between the third and seventh day of illness. This tends to coincide with resolution of fever [51].

Blood levels of soluble dengue NS1 protein $(>600 \mathrm{ng} / \mathrm{mL})$ were predictive of DHF in one study of Thai children with secondary dengue 2 virus infections [52].

\section{Plasma leakage}

Plasma leakage is the most specific and lifethreatening feature of DHF. The increase in vascular permeability develops over a period of 24 to 48 hours. Shock may develop in patients with marked plasma leakage, especially if supportive treatment is delayed. This clinical presentation is referred to as "dengue shock syndrome" (DSS) and is associated with a casefatality rate as high as 12 percent in some studies, even with aggressive therapy [53].

Plasma leakage usually occurs between three and seven days after the onset of illness. This coincides with defervescence, severe thrombocytopenia, and elevation of aminotransferases [48]. Abdominal pain is also reported to precede the onset of plasma leakage in approximately 60 percent of patients with DHF $[\mathbf{5 4 , 5 5 , 5 6 ]}$. The presence of intense abdominal pain, persistent vomiting, and marked restlessness or lethargy, especially coinciding with defervescence, should alert the clinician to possible impending dengue shock syndrome [57].

Chest radiography and chest/abdominal ultrasound are the imaging modalities useful for detection of plasma leakage in DHF. Right lateral decubitus chest radiograph was sensitive for detection of pleural effusion, but ultrasound was useful for detecting larger effusions and also had the advantages of evaluating for presence of peritoneal fluid. Plasma leakage was detected by ultrasound as early as three days after the onset of fever; 
pleural effusions were more common than ascites or edema of the gallbladder wall [58].

\section{Hemorrhagic manifestations}

The severity of hemorrhagic manifestations is quite variable among patients with DHF. Previous studies reported spontaneous petechiae or ecchymoses in approximately one-half of adults and children with DHF $[\mathbf{5 4 , 5 5}]$. Other less-frequent hemorrhagic manifestations reported in these studies included: hematemesis (15 to 30 percent of subjects), menorrhagia (40 percent of adult women), melena (5 to 10 percent), and epistaxis (10 percent).Hemorrhagic manifestations are also common in dengue fever [43,59]; this can be severe, requiring hospitalization and transfusion in rare cases [60].

\section{Laboratory testing}

Confirmation of acute dengue virus infection is most frequently accomplished using serology [51,61]. Tests for detection of viral RNA or NS1 antigen are commercially available and more successful than serology in detecting dengue virus infection in the early stages [62]. The following diagnostic approach is recommended, to the patient with suspected dengue if laboratory support is available $[\mathbf{5 1}, \mathbf{6 1}, \mathbf{6 3}]$ :

- An acute phase, serum or plasma sample should be obtained. If the acute phase sample is obtained $\geq 3$ days after the onset of illness, the IgM immunoassay (MAC-ELISA or equivalent) is the procedure of choice for rapid confirmation of the diagnosis. The potential for a falsenegative result remains elevated within the first six days of illness.

- If the acute phase sample is obtained within the first three days after the onset of illness or if the sample is obtained within the first six days of illness and there is a negative $\operatorname{IgM}$ assay result, testing for the presence of the dengue viral RNA or NS1 antigen has the highest diagnostic yield.

- To confirm a positive IgM result or if initial testing is negative in a patient with suspected dengue virus infection, a convalescent phase serum sample should be obtained at least 10 to 14 days after the acute phase serum. The acute and convalescent specimens should be analyzed together by a hemagglutination inhibition (HI) or enzyme immunoassay to provide definitive serologic testing for acute dengue virus infection.

\section{Serologic testing}

The most frequently used serologic tests for the diagnosis of acute dengue virus infection are the $\mathrm{HI}$ assay and IgG or IgM enzyme immunoassays. Complement fixation and neutralizing antibody assays are more technically demanding and are used in specialized laboratories only.

The HI assay remains the gold standard for serologic testing for dengue virus-specific antibodies. Analysis of paired acute and convalescent serum samples is essential; a fourfold or greater rise in HI antibody titer between acute and convalescent samples defines acute infection.

The antibody response depends on whether the patient has primary or secondary dengue virus infection. In primary infection, HI antibodies develop relatively late (after the fifth day of illness) and reach titers of less than 1:1250 in the convalescent phase. In secondary infection, HI antibodies rise early and reach titers above $1: 1250$ (often $1: 10,240$ or higher) in the convalescent phase [51].

Immunoassays for the detection of dengue virusspecific IgG antibodies have demonstrated sensitivity and specificity of approximately 99 percent and 96 percent, respectively, compared with the HI assay [64]. Testing of paired acute and convalescent serum samples is required for the diagnosis of acute dengue virus infection using the IgG ELISA.

A component of the antibody response is dengue virus serotype-specific; a substantial portion of the antibody response has cross-reactivity with other dengue virus serotypes and even other flaviviruses. Cross-reactivity is more problematic in secondary dengue virus infection and also in individuals who have been immunized with vaccines against other flaviviruses such as Japanese encephalitis virus [65]. Although neutralizing antibody assays have greater specificity than $\mathrm{HI}$ or ELISA assays, serologic assays cannot be relied on for identification of the infecting dengue virus serotype [66].

\section{Virus detection}

Isolation of dengue virus or detection of dengue viral RNA or protein in an acute phase serum or tissue specimen provides the most definitive confirmation of infection [61]. A real-time RTPCR assay kit developed by the Disease Control and Prevention (CDC) was approved by the FDA in 2012 for diagnostic use in the United States [67]. In both prospective and retrospective 
testing, the sensitivity and specificity of the test were $\geq 98$ percent compared with a reference method [68]. RT-PCR is the only method that can detect virus within a clinically meaningful time frame (one to two days or less) [70,71,72] and it has comparable sensitivity to viral isolation $[69,73]$.

Virus isolation is generally performed only for epidemiologic or research purposes. Serum and plasma are the preferred specimens for virus isolation, although virus can occasionally be isolated from liver tissues after clearance of virus from the serum [74]. Virus isolation typically requires one to two weeks [75].

Regardless of the specific method used, optimal detection is achieved when specimens are obtained early after the onset of symptoms, during the febrile period. In one study of children in Thailand, dengue viruses could be isolated from all plasma samples obtained at least two days before defervescence but from no samples obtained two or more days after fevers resolved [9].

The dengue viral nonstructural protein 1 (NS1) can be detected in plasma, especially during the first five to six days of illness. In one study, high levels early in infection were associated with DHF [52]. Two assays have become commercially available outside the United States. The sensitivity of these assays for diagnosis of acute dengue infection at the time of hospital admission is 50 to 70 percent, with specificity $>95$ percent $[\mathbf{7 6 , 7 7 ]}$. However, neither assay is formulated to provide either identification of the specific dengue virus serotype or quantitative measurement of soluble NS1 protein levels.

For many resource-limited dengue endemic countries, routine laboratory testing is not readily available. One study of 1250 children aged 2 months to 10 years presenting to a pediatric hospital in southern Vietnam evaluated whether an assessment tool designed for first-level healthcare workers, using only clinical signs, could appropriately classify and guide management of acute illnesses in an endemic area [58].

\section{PREVENTION}

Dengue prevention currently relies on public health and community based A.aegypti control programs to remove and destroy mosquitobreading sites [78].
Public health approaches for prevention of dengue infection in endemic areas include control of Aedes mosquitoes and development of vaccines.

\section{Mosquito control}

Mosquito control is the most effective approach for prevention of dengue transmission.

Insecticide spraying in response to dengue outbreaks is not highly effective against $A$. aegypti mosquitoes, which frequently breed inside houses [79,80]. Community-based approaches involving education of the population in efforts to reduce breeding sites, such as discarded tires and other containers that accumulate standing water, have shown some promise [79]. Indoor insecticidal fogging may be effectual.

\section{Vaccination}

Infection with dengue virus provides long-term protection against the particular serotype that caused the disease, supporting the feasibility of a dengue vaccine. However, it provides only shortlived immunity to the other three dengue virus serotypes. In view of the association of dengue hemorrhagic fever (DHF) with previous exposure to dengue viruses and the recognition that all four serotypes are capable of inducing DHF, it is the general consensus in the scientific and public health communities that any candidate vaccine should produce protective immunity against all four serotypes. Since waning immunity might also increase the risk for DHF in vaccine recipients, vaccine-induced protective immunity should also be long lived [81].

No licensed vaccine is available for preventing dengue $[\mathbf{8 2 , 8 3}]$.

\section{Travelers}

Most travelers from non-endemic countries are at exceedingly low risk for DHF because they lack previous exposure to dengue viruses.

Travelers are well advised to wear clothing that reduces the amount of exposed skin. Also advised to protect themselves by using repellents and insecticidal sprays indoor. Bed netting is of little use since the mosquitoes are most active during the daytime [80].

\section{Treatment}

There is no specific therapy available for dengue virus infections, it is important to exclude other treatable diagnoses. 


\section{Management of fever}

Fever and myalgia can be managed with acetaminophen (maximum $60 \mathrm{mg} / \mathrm{kg} /$ day in children or $4 \mathrm{~g} /$ day in adults). Aspirin or nonsteroidal antiinflammatory agents should generally be avoided because of the risk of bleeding complications and in children because of the potential risk of Reye's syndrome.

Patients with dengue fever should maintain oral fluid intake to avoid dehydration. The most important measure to assist the patient with suspected dengue fever is to carefully evaluate the patient for impending complications or early evidence of dengue hemorrhagic fever (DHF) [1].

\section{Management of significant bleeding}

Gastrointestinal bleeding, epistaxis, or menorrhagia in patients with DHF (and occasionally in patients with dengue fever) can be severe enough to require blood transfusion. In these circumstances, blood replacement should be performed with $5 \mathrm{~mL} / \mathrm{kg}$ of packed red blood cells (or $10 \mathrm{~mL} / \mathrm{kg}$ whole blood). The clinical response and post-transfusion hematocrit should be monitored. Use of a histamine $\mathrm{H} 2$ receptor antagonist or proton pump inhibitor is reasonable in patients with gastrointestinal bleeding, although there is no evidence of benefit. Platelet transfusions have not been shown to be effective at preventing or controlling hemorrhage but may be warranted in patients with severe thrombocytopenia $\left(<10,000 / \mathrm{mm}^{3}\right)$ and active bleeding. Prophylactic platelet transfusions in patients with severe thrombocytopenia but without active bleeding are generally not recommended $[84,85]$. Administration of intravenous vitamin $\mathrm{K} 1$ is recommended for patients with severe liver dysfunction or prolonged prothrombin time [31].

\section{Management of plasma leakage}

Plasma leakage in DHF is important to manage with intravascular volume repletion to prevent or reverse hypovolemic shock [86]. In mild cases, particularly when medical attention is received early, oral rehydration may be sufficient. However, in patients with established intravascular volume loss, intravenous fluid administration is recommended. Blood transfusion is appropriate in patients with significant bleeding or those who have low hematocrit and fail to improve despite fluid resuscitation. Subsequent hematocrit measurements must be interpreted with caution since it is critical to assess the adequacy of both blood and fluid repletion; in complex cases, it can be challenging to distinguish whether a decrease in hematocrit reflects volume repletion or blood loss [86].

\section{Treatment of shock}

For patients with shock, initial resuscitation with normal saline or Ringer's lactate $(10 \mathrm{~mL}$ per $\mathrm{kg}$ of body weight for children or $500 \mathrm{~mL}$ for adults), preferably with 5 percent dextrose, is recommended, either as an infusion over the first hour or as a bolus (infused over 10 to 15 minutes) for patients in profound shock. A second infusion of an equal volume is recommended in patients who remain in shock [84].

There has been debate as to whether crystalloids or colloids should be used for volume replacement in critically ill patients. Three randomized trials have investigated the effect of different fluid regimens on outcome $[\mathbf{8 7}, \mathbf{8 8}]$. The largest of these studies was a double-blind randomized comparison of three fluids for initial resuscitation of 512 Vietnamese children with dengue shock syndrome [89]. Three hundred eighty-three patients with moderate shock were assigned to Ringer's lactate or one of two different colloid solutions: 6 percent dextran 70 or 6 percent hydroxyethyl starch. One hundred twenty-nine patients with severe shock were randomized to receive one of the two colloids. The treatment regimen closely followed the WHO protocol, with $15 \mathrm{~mL} / \mathrm{kg}$ administered over the first hour and $10 \mathrm{~mL} / \mathrm{kg}$ over the second hour. Only one patient died. This trial established that Ringer's lactate is a safe, effective, and inexpensive alternative in initial resuscitation of patients with moderate shock. In patients with severe shock, dextran and starch performed similarly, although dextran was associated with more hypersensitivity reactions [51,90].

In patients who remain in shock despite the two initial boluses of crystalloid, it is preferred to switch to a colloid solution $(10 \mathrm{mg} / \mathrm{kg}$ over the next hour). 10 percent dextran 40 in normal saline is the colloid of choice. Switching to a colloid solution is also appropriate in patients who have signs of fluid overload (eg, puffy eyelids, distended abdomen, tachypnea, or dyspnea). Patients who have persistent hypo perfusion with falling hematocrit require blood transfusion. Other possible complications, such as acidosis, hypoglycemia, or hypocalcemia, should also be investigated and corrected as needed [90].

Once blood pressure has been restored, intravenous fluids should be continued but the infusion rate should be gradually reduced over the next 24 to 36 hours. The patient's clinical 
condition, including vital signs, urine output, and hematocrit, should be checked prior to each reduction in the infusion rate. Close clinical observation is essential, even after normal blood volume is restored, because patients can develop recurrent shock over the 24 hours after the initial resuscitation, which represents the period of increased vascular permeability in DHF. Most patients who present for medical attention before profound shock develops and who receive appropriate fluid therapy will recover quickly.

The fluids that are lost into potential spaces (eg, pleura, peritoneum) during the period of plasma leakage are rapidly reabsorbed. Thus, intravenous fluid supplementation should be discontinued once patients have passed the period of plasma leakage. Usually no more than 48 hours of intravenous fluid therapy are required. Excessive fluid administration after this point can precipitate hypervolemia and pulmonary edema [90].

\section{Adjunctive therapies}

The basis of DHF pathogenesis is hypothesized to be immunologic, which has led to interest in immune-modulatory drugs for therapy.

Several trials have demonstrated that corticosteroids are no more effective than placebo in reducing death, need for blood transfusion, or serious complications $[\mathbf{9 1 , 9 2 , 9 3 ]}$.

Other modalities, including intravenous immunoglobulins, pentoxifylline, and activated factor VII, have also been proposed for use $[94,95,96]$. However, no benefits have been established in a controlled evaluation.

\section{REFERENCES}

1- Tsai TF, Vaughn DW, Solomon T. Flaviviruses . In Principles and Practice in Infectious Diseases. Mandell GL, Bennet JE, Dolin R. Sixth edition, Philadelphia, Penselvania, 2005. P1926-1950.

2- Bhatt S, Gething PW, Brady OJ, MessinaJP, Farlow AW, Moyes CL,et al.The global distribution and burden of dengue. Nature 2013; 496:504.

3- Henchal EA, Putnak JR. The dengue viruses. Clin Microbiol Rev 1990; 3:376.

4- Wilder-Smith A, Schwartz E. Dengue in travelers. N Engl J Med 2005; 353:924.

5- Harrington LC, Scott TW, Lerdthusnee K, Colman RC, Costero A, Clark GG, et al. Dispersal of the dengue vector Aedes aegypti within and between rural communities. Am J Trop Med Hyg 2005; 72:209.
6- Scott TW, Amerasinghe PH, Morrison AC, Lorenz LH, Clark GG,Strickman D, et al. Longitudinal studies of Aedes aegypti (Diptera: Culicidae) in Thailand and Puerto Rico: blood feeding frequency. J Med Entomol 2000; 37:89.

7- Kuno G. Review of the factors modulating dengue transmission. Epidemiol Rev 1995; 17:321.

8- Gubler DJ. Epidemic dengue and dengue hemorrhagic fever: a global public health problem in the 21 st century. In: Emerging Infections I, Scheld WM, Armstrong D, Hughes JM (Eds), ASM Press, Washington, DC 1998. p.1

9- Vaughn DW, Green S, Kalayanarooj S, Bruce L Innis, Suchitra N, Saroj S, et al. Dengue in the early febrile phase: viremia and antibody responses. J Infect Dis 1997; 176:322.

10- Langgartner J, Audebert F, Scholmerich J, Gluck T. Dengue virus infection transmitted by needle stick injury. J Infect. 2002;44:269-270.

11- Endy TB, Chunsuttiwat S, Nisalak A,Libarty TH, Green S, Rothman AL, et al. Epidemiology of inapparent and symptomatic acute dengue virus infection: A prospective study of primary school children in Kamphaen Phet, Thiland. Am J Epidemiol. 2002; 156: 40-51.

12- Nguyet MN, Duong TH, Trung VT, Nguyen TH, Trann CN, Long VT, et al. Host and viral features of human dengue cases shape the population of infected and infectious Aedes aegypti mosquitoes. Proc Natl Acad Sci U S A 2013; 110:9072.

13- Wu SJ, Grouard-Vogel G, Sun W ,Mascola JR, Brachtel E,Putvatana R, et al. Human skin Langerhans cells are targets of dengue virus infection. Nat Med. 2000; 6:816-820.

14- Jessie K, Fong MY, Devi S, Wong KT. Localization of dengue virus in naturally infected human tissues by immunohistochemistry and in situ hypbridization. J Infect Dis. 2004; 189:14111418.

15- Malheiros SMF, Oliveira ASB, Schmidt B, Lima JG, Gabai AA. Dengue: Muscle biopsy findings in 15 patients, Arq Neuropsiquiatr. 1993; 51:159.

16- Lum LCS, Lam SK, Choy YS, George R,Harun F. Dengue encephalitis: A true entity? Am J Trop Med Hyg. 1996; 54: 256.

17- Solomon T, Dung NM, Vaughn DW, Kneen R, Thao LT, Raengsakulrach B, et al. Neurological manifestations of dengue infection. Lancet. 2000; 355:1053-1059.

18- Monath TP. Early indicators in acute dengue infection. Lancet. 1997;350: 1719-1720.

19- Halstead SB. Antibody, macrophages, dengue virus infection, shock and hemorrhage: A pathogenic cascade.Rev Infect Dis.1989; 11(suppl):s830-s839. 
20-Mongkolsapaya J, Dejnirattisai W, Xu XN, Vasanawathana S, Tangthawornchaikul N, Chairunsri A, Sawasdivorn S, et al.Original antigenic sin andapoptosis in the pathogenesis of dengue hemorrhagic fever. Nat Med. 2003;9(7):921-7.

21- Rothman AL. Immunology and immunopathogenesis of dengue disease. Adv Virus Res. 2003; 60: 397419.

22- Bokicsch AV, Top FH, Russel PK, Dixon FG, Muller-Eberhard HJ. The pote.ntial pathogenic role of complement in dengue hemorrhagic shock syndrome. N Eng J Med. 1973; 289: 996

23- Kabra SK, Junija R, Madhulika, Jain Y, Singhal T ,Dar L, et al. Myocardial dysfunction in children with dengue hemorrhagic fever. Natl Med J India. 1998; 11:59.

24- Huang YH, Lie HY, Liu HS, Lin YS, Chin SH, Liu CC, et al. Tissue plasminogen activator induced by dengue virus infection of human endothelial cells. J Med Virol. 2003; 70:610-616.

25- Krishnamurti C, Kalanayarooj S, Cutting MA, Peat RA, Rothwell SW, Reid TJ, et al. Mechanism of hemorrhage in dengue without circulatory collapse. Am J Trop Med Hyg. 2001; 65: 840-847.

26- Mairuhu AT, Mac Gillavry MR, Stiati TE, Soemantri A, ten Cat H,Brandjes DP, et al. Is clinical outcome of dengue virus infections influenced by coagulation and fibrinolysis? A critical review of the evidence. Lancet Infect Dis. 2003; 3: 33-41.

27- Falconar AKI. The dengue virus nonstructural- 1 protein (NS1) generates antibodies to common epitopes on human blood clotting, integrin/ adhesion proteins and bind to human endothelial cells: potential implications in hemorrhagic fever pathogenesis. Arch Virol. 1997; 142: 897.

28- Kliks SC, Nisalka A, Brandt WE, Wahl L, Burke DS. Antibody dependent enhancement of dengue virus growth in human monocytes as a risk factor for dengue hemorrhagic fever. Am J Trop Med Hyg. 1989; 40: 444.

29- Halsted SB,. Neutralization of antibody-dependent enhancement of dengue virus. Adv Virus Res. 2003; 60:421-467.

30- Simmons CP, Farrar JJ, Nguyen vV, Wills B. Dengue. N Engl J Med 2012; 366:1423.

31- WHO Regional Office for Southeast Asia. Comprehensive guidelines for prevention and control of dengue and dengue haemorrhagic fever. Revised and expanded version. SEARO Technical Publication Series, New Delhi, India 2011.
32- Deen JL, Harris E, Wills B, Balmaseda A, Hammond SN, Rocha C, et al. The WHO dengue classification and case definitions: time for a reassessment. Lancet 2006; 368:170.

33- SABIN AB. Research on dengue during World War II. Am J Trop Med Hyg 1952; 1:30.

34-Vaughan DW, Green S, Kalayanarooj S, Innis BL, Nimmannitya S, Suntayakom S, et al. Dengue viremia titer, antibody response pattern and virus serotype correlate with disease severity. J Infect Dis. 2000; 181: 2-9.

35- Rigau-Pérez JG. The early use of break-bone fever (Quebranta huesos, 1771) and dengue (1801) in Spanish. Am J Trop Med Hyg 1998; 59:272.

36- Shirtcliffe P, Cameron E, Nicholson KG, Wiselka MJ. Don't forget dengue! Clinical features of dengue fever in returning travellers. $J R$ Coll Physicians Lond 1998; 32:235.

37- Schwartz E, Mendelson E, Sidi Y. Dengue fever among travelers. Am J Med 1996; 101:516.

38- Sharp TW, Wallace MR, Hayes CG, Sanchez JL, DeFraites RF, Arthur RR, et al. Dengue fever in U.S. troops during Operation Restore Hope, Somalia, 1992-1993. Am J Trop Med Hyg 1995; 53:89.

39-Cobra C, Rigau-Pérez JG, Kuno G, Vorndam V. Symptoms of dengue fever in relation to host immunologic response and virus serotype, Puerto Rico, 1990-1991. Am J Epidemiol 1995; 142:1204.

40- Garcia-Rivera EJ, Rigau-Perez JG. Dengue severity in the elderly in Puerto Rico. Rev Panama Salud Publica. 2003; 13:362-368.

41- Kerdpanich A, Watanaveeradej V, Samakoses R, et al. Perinatal dengue infection. Southeast Asian J Trop Med Public Health. 2001; 32: 488:493.

42- Sharma JB, Gulati N. Potential relationship between dengue fever and neural tube defects in a northern district of India. Int J Gynacol Obst. 1992;39:291-295.

43- Srikiatkhachorn A, Gibbons RV, Green S, Libarty DH, Thomas SJ, Endy TP, et al. Dengue hemorrhagic fever: the sensitivity and specificity of the world health organization definition for identification of severe cases of dengue in Thailand, 1994-2005. Clin Infect Dis 2010; 50:1135.

44- Kuo C-H, Tai D-I, Chang-Chien C-S, Lan CK, Chiou SS, Liaw YF. Liver biochemical tests and dengue fever. AM J Trop Med Hyg. 1992; 47: 265.

45- Hommel D, Talarmin A, Deubel V, Reynes JM, Drouet MT, Sarthou JL, et al. Dengue encephalitis in French Guiana. Res Virol. 1998; 149:235-238. 
46- Ramos C, Sanchez G, Pando RH, Baquera J, Hemandez D, Mota J, et al. Dengue virus in the brain of a fatal case of hemorrhagic dengue fever. $J$ Neurvirol. 1998; 4:465-468.

47- Trofa AF, DeFraites RF, Smoak BL, Kanesathasan N, King AD, Burrous JM, et al. Dengue fever in US military personnel in Haiti. JAMA 1997; 277:1546.

48- Kalayanarooj S, Vaughn DW, Nimmannitya S, Green S,Suntayakorn S, Kunentrasai N, et al. Early clinical and laboratory indicators of acute dengue illness. J Infect Dis 1997; 176:313.

49- Potts JA, Rothman AL. Clinical and laboratory features that distinguish dengue from other febrile illnesses in endemic populations. Trop Med Int Health 2008; 13:13. 28.

50- Halstead SB. Dengue. Lancet 2007; 370:1644.

51- WHO. Dengue hemorrhagic fever: diagnosis, treatment, prevention, and control. 2nd ed. Geneva: World Health Organization, 1997.

52- Libraty DH, Young PR, Pickering D, Endy TP, Kalayanarooj S, Green S, et al. High circulating levels of the dengue virus nonstructural protein NS1 early in dengue illness correlate with the development of dengue hemorrhagic fever. J Infect Dis 2002; 186:1165.

53- Tassniyom S, Vasanawathana S, Chirawatkul A, Rojanasuphot S. Failure of high-dose methylprednisolone in established dengue shock syndrome: a placebo-controlled, double-blind study. Pediatrics 1993; 92:111.

54- Díaz A, Kourí G, Guzmán MG, Lobaina L ,Bravo J, Ruitz A, et al. Description of the clinical picture of dengue hemorrhagic fever/dengue shock syndrome (DHF/DSS) in adults. Bull Pan Am Health Organ 1988; 22:133.

55- Guzmán MG, Kourí G, Martínez E, et al. Clinical and serologic study of Cuban children with dengue hemorrhagic fever/dengue shock syndrome (DHF/DSS). Bull Pan Am Health Organ 1987; 21:270.

56- Khor BS, Liu JW, Lee IK, Yang KD. Dengue hemorrhagic fever patients with acute abdomen: clinical experience of 14 cases. Am J Trop Med Hyg 2006; 74:901.

57- Rigau-Pérez JG, Laufer MK. Dengue-related deaths in Puerto Rico, 1992-1996: diagnosis and clinical alarm signals. Clin Infect Dis 2006; 42:1241.
58- Srikiatkhachorn A, Krautrachue A, Ratanaprakarn W, Waranagkana W, Wongtaparadit L, Nithipanya $\mathrm{N}$, et al. Natural history of plasma leakage in dengue hemorrhagic fever: a serial ultrasonographic study. Pediatr Infect Dis J 2007; 26:283.

59- Cao XT, Ngo TN, Wills B, et al. Evaluation of the World Health Organization standard tourniquet test and a modified tourniquet test in the diagnosis of dengue infection in Viet Nam. Trop Med Int Health 2002; 7:125.

60- Phuong CX, Nhan NT, Kneen R, Thuy PT, van Thien C, Nga NT, et al. Clinical diagnosis and assessment of severity of confirmed dengue infections in Vietnamese children: is the world health organization classification system helpful? Am J Trop Med Hyg 2004; 70:172.

61- Rigau-Pérez JG, Gubler DJ, Vorndam AV, Clark GG. Dengue surveillance--United States, 19861992. MMWR CDC Surveill Summ 1994; $43: 7$.

62- Blacksell SD, Mammen MP Jr, Thongpaseuth S, Gibbson RV, Jarman RG, Jenjaroen K, et al. Evaluation of the Panbio dengue virus nonstructural 1 antigen detection and immunoglobulin M antibody enzyme-linked immunosorbent assays for the diagnosis of acute dengue infections in Laos. Diagn Microbiol Infect Dis 2008; 60:43.

63- Taraphdar D, Sarkar A, Mukhopadhyay BB, Chatterjee S. A comparative study of clinical features between monotypic and dual infection cases with Chikungunya virus and dengue virus in West Bengal, India. Am J Trop Med Hyg 2012; $86: 720$.

64- McBride WJ, Mullner H, LaBrooy JT, Wronski I. The 1993 dengue 2 epidemic in North Queensland: a serosurvey and comparison of hemagglutination inhibition with an ELISA. Am J Trop Med Hyg 1998; 59:457.

65- Yamada K, Takasaki T, Nawa M,Yabe S, Kurane I. Antibody responses determined for Japanese dengue fever patients by neutralization and hemagglutination inhibition assays demonstrate cross-reactivity between dengue and Japanese encephalitis viruses. Clin Diagn Lab Immunol 2003; 10:725.

66- van Panhuis WG, Gibbons RV, Endy TP, Rothman AL, Srikiathhachorn A, Nisalak A, et al. Identifying the serotype associated with dengue virus infections on the basis of pre- and postinfection neutralizing antibody titers. $J$ Infect Dis 2010; 202:1002. 
67- http://www.cdc.gov/media/releases/2012/ p0620_ dengue_test.html (Accessed on July 17, 2012).

68- Centers for Disease Control and Prevention. CDC DENV-1-4 Real-Time RT-PCR Assay. Package insert. http://www.cdc.gov/dengue/resources/rt_ pcr/ CDCPackageInsert.pdf (Accessed on November 15, 2012).

69- Deubel V. The contribution of molecular techniques to the diagnosis of dengue infection. In: Dengue and Dengue Hemorrhagic Fever, Gubler DJ, Kuno $\mathrm{G}$ (Eds), CAB International, $\mathrm{CAB}$ International 1997. p.335.

70- Chien LJ, Liao TL, Shu PY, et al. Development of real-time reverse transcriptase PCR assays to detect and serotype dengue viruses. J Clin Microbiol 2006; 44:1295.

71- Johnson BW, Russell BJ, Lanciotti RS. Serotypespecific detection of dengue viruses in a fourplex real-time reverse transcriptase PCR assay. J Clin Microbiol 2005; 43:4977.

72- de Oliveira Poersch C, Pavoni DP, Queiroz MH, de Borba L,Goldenberg S, dosSantos CND, et al. Dengue virus infections: comparison of methods for diagnosing the acute disease. J Clin Virol 2005; $32: 272$.

73- Sudiro TM, Ishiko H, Green S, Vaughn DW,Nisalak A, Kalayanarooj S, et al. Rapid diagnosis of dengue viremia by reverse transcriptase-polymerase chain reaction using 3'noncoding region universal primers. Am J Trop Med Hyg 1997; 56:424.

74- Rosen L, Khin MM, U T. Recovery of virus from the liver of children with fatal dengue: reflections on the pathogenesis of the disease and its possible analogy with that of yellow fever. Res Virol 1989; 140:351.

75- Rosen L. The use of Toxorhynchites mosquitoes to detect and propagate dengue and other arboviruses. Am J Trop Med Hyg 1981; 30:177.

76- Guzman MG, Jaenisch T, Gaczkowski R, et al. Multi-country evaluation of the sensitivity and specificity of two commercially-available NS1 ELISA assays for dengue diagnosis. PLoS Negl Trop Dis 2010; 4.

77- Blacksell SD, Jarman RG, Gibbons RV, et al. Comparison of seven commercial antigen and antibody enzyme-linked immunosorbent assays for detection of acute dengue infection. Clin Vaccine Immunol 2012; 19:804.

78- Reiter P, Gubler DJ. Surveillance and control of urban dengue vectors. In: Gubler DJ, Kumo G, eds. Dengue and dengue hemorrhagic fever. New York: CAB International; 1997:425.
79- Gubler DJ. Aedes aegypti and Aedes aegyptiborne disease control in the 1990s: top down or bottom up. Charles Franklin Craig Lecture. Am J Trop Med Hyg 1989; 40:571.

80- Halstead SB. Selective primary health care: strategies for control of disease in the developing world. XI. Dengue. Rev Infect Dis 1984; 6:251.

81- Monath TP. Dengue and yellow fever--challenges for the development and use of vaccines. $N$ Engl J Med 2007; 357:2222.

82- Durbin AP, Whitehead SS. Dengue vaccine candidates in development. Curr Top Microbiol Immunol 2010; 338:129.

83- Guirakhoo F, Pugachev K, Zhang Z, et al. Safety and efficacy of chimeric yellow Fever-dengue virus tetravalent vaccine formulations in nonhuman primates. J Virol 2004; 78:4761.

84- Dengue: guidelines for diagnosis, treatment, prevention and control - new edition. World Health Organization, Geneva 2009, p. 1.

85- Thomas L, Kaidomar S, Kerob-Bauchet B, et al. Prospective observational study of low thresholds for platelet transfusion in adult dengue patients. Transfusion 2009; 49:1400.

86- Nimmannitya S. Dengue hemorrhagic fever: Diagnosis and management. In: Dengue and Dengue Hemorrhagic Fever, Gubler DJ, Kuno G (Eds), CAB International, Wallingford 1997. p.133.

87- Ngo NT, Cao XT, Kneen R, et al. Acute management of dengue shock syndrome: a randomized double-blind comparison of 4 intravenous fluid regimens in the first hour. Clin Infect Dis 2001; 32:204.

88- Dung NM, Day NP, Tam DT, Loan HT,Chau HT, Minh LN, et al. Fluid replacement in dengue shock syndrome: a randomized, double-blind comparison of four intravenous-fluid regimens. Clin Infect Dis 1999; 29:787.

89- Wills BA, Nguyen MD, Ha TL, et al. Comparison of three fluid solutions for resuscitation in dengue shock syndrome. N Engl J Med 2005; 353:877.

90- Rothman AL, Srikiatkhachorn, A and Kalayanarooj S. Prevention and treatment of dengue virus infection. Up To Date Jul 2015. www.uptodate.com

91- Panpanich R, Sornchai P, Kanjanaratanakorn K. Corticosteroids for treating dengue shock syndrome. Cochrane Database Syst Rev 2006; : CD003488.

92- Tam DT, Ngoc TV, Tien NT, Farrar JJ, Simmon PC, Wolbers M, et al. Effects of short-course oral corticosteroid therapy in early dengue infection in Vietnamese patients: a randomized, placebocontrolled trial. Clin Infect Dis 2012; 55:1216. 
93- Zhang F, Kramer CV. Corticosteroids for dengue infection. Cochrane Database Syst Rev 2014; 7: CD003488.

94- Dimaano EM, Saito M, Honda S,Miranda EA, Alonzo MT,Valerio MD, et al. Lack of efficacy of high-dose intravenous immunoglobulin treatment of severe thrombocytopenia in patients with secondary dengue virus infection. Am J Trop Med Hyg 2007; 77:1135.
95- Chuansumrit A, Wangruangsatid S, Lektrakul Y, Chua M,Zeta Cpending MR, Bech OM.. Control of bleeding in children with Dengue hemorrhagic fever using recombinant activated factor VII: a randomized, double-blind, placebo-controlled study. Blood Coagul Fibrinolysis 2005; 16:549.

96- Salgado D, Zabaleta TE, Hatch S, Vega MR Rodriguez J. Use of pentoxifylline in treatment of children with dengue hemorrhagic fever. Pediatr Infect Dis J 2012; 31:771. 